\title{
GPPS-CH-2020-0042
}

\section{DESIGN OF A TRANSONIC BOUNDARY LAYER INGESTING FUSELAGE FAN}

\author{
Alejandro Castillo Pardo \\ Whittle Laboratory \\ University of Cambridge \\ ac2181@cam.ac.uk \\ Cambridge CB3 ODY, UK
}

\author{
Cesare A. Hall \\ Whittle Laboratory \\ University of Cambridge \\ cah1003@cam.ac.uk \\ Cambridge CB3 ODY, UK
}

\begin{abstract}
Boundary Layer Ingesting (BLI) aircraft configurations could provide significant reductions in fuel burn and pollutant emissions. A BLI fuselage propulsor features a fan at the back of the aircraft to ingest and reenergise the fuselage boundary layer. The concept being developed by the EU CENTRELINE project features a single electrically driven fan that ingests $360^{\circ}$ of the aft fuselage boundary layer. Consequently, the fan face distortion at cruise is close to radial.

This paper presents the design philosophy for a transonic BLI fuselage fan that performs well across the aircraft flight envelope. CFD computations have been carried out for two transonic fan stages. A datum wide-chord fan design matched to undistorted inflow has been computed for uniform and BLI inlet conditions at cruise. The changes in flow structures and loss sources due to BLI have been used to design a distortion tolerant transonic fan matched to BLI. The new design improves the efficiency when operating on the cruise working line, without compromising flow capacity or stability margin. This is shown to enable improved off-design performance. Overall, the redesign demonstrates that it is possible to design a transonic aft fuselage BLI fan that delivers high efficiency with improved operating range.
\end{abstract}

\section{INTRODUCTION}

Boundary Layer Ingesting (BLI) aircraft configurations are characterised by the integration of the propulsion system into the fuselage. The propulsor ingests and re-energises the low-momentum fluid contained within the fuselage boundary layer, enhancing the propulsive efficiency of the system. BLI installations can be classified in two groups. The first group, referred as $180^{\circ}$ or semi-buried BLI, creates a highly mixed circumferential and radial distortion (Hall, et al., 2009; Uranga, et al., 2014). The second group, denominated $360^{\circ}$ BLI, ingests the $360^{\circ}$ fuselage boundary layer. In such an arrangement the distortion at the fan face during cruise is essentially radial. The propulsive fuselage concept developed by the EU CENTRELINE project (Seitz, et al., 2018) is part of the second group. This configuration, shown in Figure 1, is the object of study of this paper. It features an electrically driven fan at the back of the aircraft that ingests the $360^{\circ}$ of the aft fuselage boundary layer. As a consequence of the radial topology of the distortion found at the fan face, losses in fan efficiency and stability margin due to BLI could be minimised through fan design.

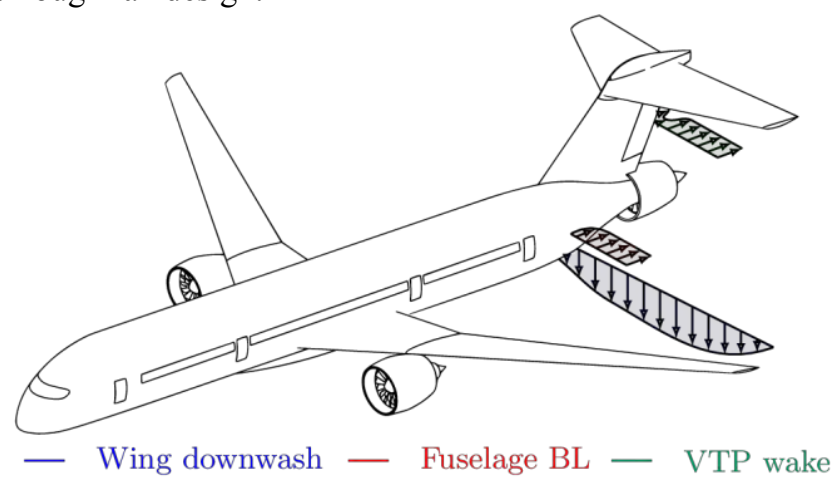

Figure 1 Sketch of sources of distortion at the inlet of CENTRELINE's fuselage fan. Adapted from

(Seitz, et al., 2018)

Relatively few studies of the effects of radial distortion on fan aerodynamics have been carried out. NASA tested in the 1970s a series of fan designs with and without radial distortion (Sandercock \& Sanger, 1974; Schmidt \& Ruggeri, 1978; Sanger, 1979). It was observed an increase in rotor incidence angles, work loading and diffusion factor in sections located within the distorted region. The flow was found to radially migrate from regions of high stagnation pressure towards low total pressure. Gunn \& Hall (2014) described a similar flow redistribution for a semi-buried installation. The flow redistribution was found to reduce the non-uniformity upstream and within a fan rotor, leading to changes in rotor incidence and work loading. 
Castillo Pardo \& Hall (2019) recently studied the aerodynamics of CENTRELINE fuselage fan. Two fan designs were commissioned and tested in an experimental low-speed BLI fan rig. The effect of a severe and continuous hub-low radial distortion was first analysed on a conventional free-vortex fan designed for clean inflow. Radial flow migration towards the hub was reported. The inner sections of the blade were found to operate at increased incidence and work loading. In contrast the tip sections were shown to operate with negative incidence and reduced loading. BLI distortion led to an overall drop in work input and efficiency. A second fan optimised for $360^{\circ}$ BLI was designed. It featured: a leading edge (LE) realigned with the inflow, midspan loaded work distribution, controlled diffusion factor through custom work and chord distribution and increased operating range of the tip sections. Castillo Pardo \& Hall (2019) reported an increase in work loading and efficiency relative to the baseline design with improved operating range.

Previous studies have mainly focused on the impact of distortion on the fan aerodynamics at design conditions. Mårtensson, et al. (2019), investigated the impact of offdesign operation on a fuselage fan and showed that the fan aerodynamics changed significtly between flight conditions. However, the design requirements for the successful offdesign operation of a fuselage fan across the operational envelope have not previously been studied. Changes in flight level and Mach number along the mission lead to changes in the ingested boundary layer combined with changes in the fan rotational speed and working line. These off-design conditions need to be accounted for during the design process to ensure that stable operation and adequate thrust are maintained whilst maximising the performance at the aerodynamic design point.

This paper starts by presenting the computational methods used for fan aerodynamic analyses. In the following section a datum wide-chord fan design, Fan A, matched to undistorted inflow is presented. Its aerodynamics are analysed for clean and cruise BLI conditions. A second design, Fan B, is then developed extrapolating the design philosophy from (Castillo Pardo \& Hall, 2019) for improved fuselage BLI performance. Numerical predictions of both fans are then compared for cruise design point conditions. In subsequent sections, the off-design performance of Fan B is presented across the aircraft flight-envelope.

Overall, this paper shows that it is possible to redesign a transonic aft fuselage BLI fan that delivers improved efficiency on the cruise working line as well as increased operating range at off-design conditions. The paper should be of interest to researchers working in the field of BLI engines and fan-distortion interaction

\section{COMPUTATIONAL METHODS}

Single-passage, steady-state simulations were carried out using Turbostream (Brandvik \& Pullan, 2011). Turbostream is a $3 \mathrm{D}$, unsteady, Reynolds-averaged Navier Stokes solver running on structured multi-block meshes. The one-equation Spalart-Allmaras turbulence model (Spalart \& Allmaras, 1992) was used for all simulations along with adaptive wall functions and a $y+$ value of approximately 5 on all solid walls.

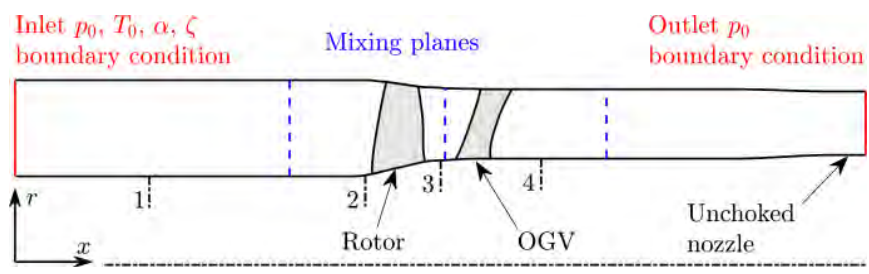

Figure 2 Meridional view of the fan computational domain showing the measuring planes

Figure 2 shows the meridional view of the computational domain. The domain was extended 1 fan diameter upstream and downstream of the fan stage to allow enough space for the fan-distortion interaction to take place. The structured multiblock computational mesh was generated using NUMECA IGG/Autogrid5 (NUMECA International, 2016, 2016). Rotor blades and outlet guide vanes (OGV) were meshed using $\mathrm{O} 4 \mathrm{H}$ topology with an $\mathrm{O}-$ mesh around each blade. In contrast, a $\mathrm{H}$ topology was used to mesh the inlet and outlet subdomains. Around 3.5 and 3.1 million nodes were used per rotor and OGV blade passage, respectively. The suitability of this numerical setup for the analysis of distortion ingesting fans has been previously shown by (Jerez Fidalgo, et al., 2012; Gunn \& Hall, 2014; Castillo Pardo \& Hall, 2019).

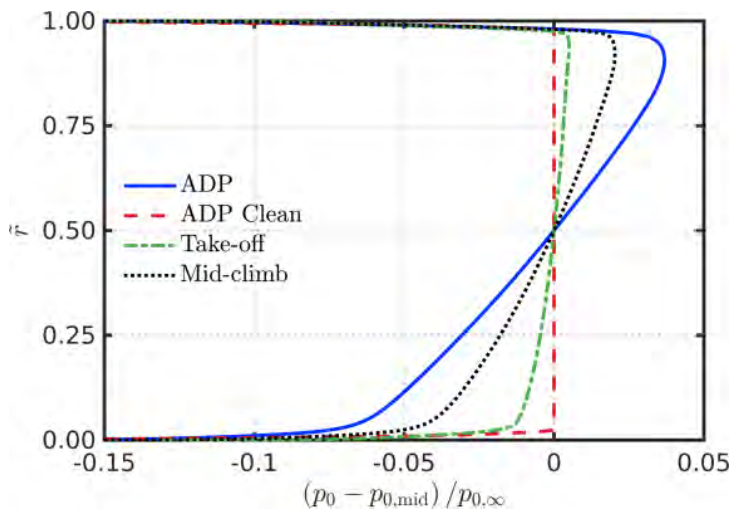

Figure 3 Profiles of stagnation pressure at the highlight plane for different operating conditions

Figure 3 presents the axisymmetric but radially nonuniform profiles of stagnation pressure found at the highlight plane of CENTRELINE's propulsor for different operating points (van Sluis, 2020). These profiles along with radial distributions of flow angles are prescribed as inlet boundary conditions of the fan numerical model. It is noted that uniform inlet properties for cruise aerodynamic design point (ADP) conditions correspond to the mass averaged properties of the non-uniform profile at design point. The operating point of the model was controlled by varying the static pressure specified at the outlet boundary of the convergent nozzle.

\section{DESIGN OF FUSELAGE FANS}

Two transonic fan stages have been designed to study the aerodynamics of BLI fuselage fans. Fan A has been developed for clean undistorted inflow at cruise ADP conditions. Fan B has been designed for improved cruise BLI performance. The focus of this work is the aerodynamics of the rotor. However, each stage has been equipped with a row of OGVs. The overall 
design parameters of both stages at cruise ADP conditions are summarised in Table 1.

\begin{tabular}{|l|c|}
\hline Flight level & $35000 \mathrm{ft}$ \\
\hline Flight Mach number & 0.82 \\
\hline Flow coefficient & 0.69 \\
\hline Stage loading coefficient & 0.45 \\
\hline Stage pressure ratio & 1.4 \\
\hline Rotor inlet tip Mach number & 1.24 \\
\hline Rotor inlet hub-to-tip-ratio & 0.51 \\
\hline Running tip clearance (\% span) & 0.2 \\
\hline Number of rotor, stator blades & 20,43 \\
\hline
\end{tabular}

Table 1 Aerodynamic design point parameter of CENTRELINE fuselage fan.

\section{Fan A}

Fan A was designed following the design guidelines proposed by Castillo Pardo \& Hall (2019) for low speed fuselage fans. The leading edge metal angle was aligned to the inlet flow to operate at minimum pressure loss incidence at the ADP. A radial distribution of work was chosen to produce a midspan loaded blade, as shown in Figure 4(a). A controlled solidity distribution was chosen to keep Lieblein's diffusion factor under 0.35 away from the endwalls. A midchord-loaded design with $5.75 \%$ thickness was chosen for the hub section, whilst a low-turning rear-loaded section with $3.1 \%$ thickness was designed for the tip. A smooth blend between mid and rear-loaded sections was carried out along the span to accommodate the incoming profile of Mach number. Rotor blade sections were radially stacked on their centroids to minimise the unsteady bending moments of the blade.
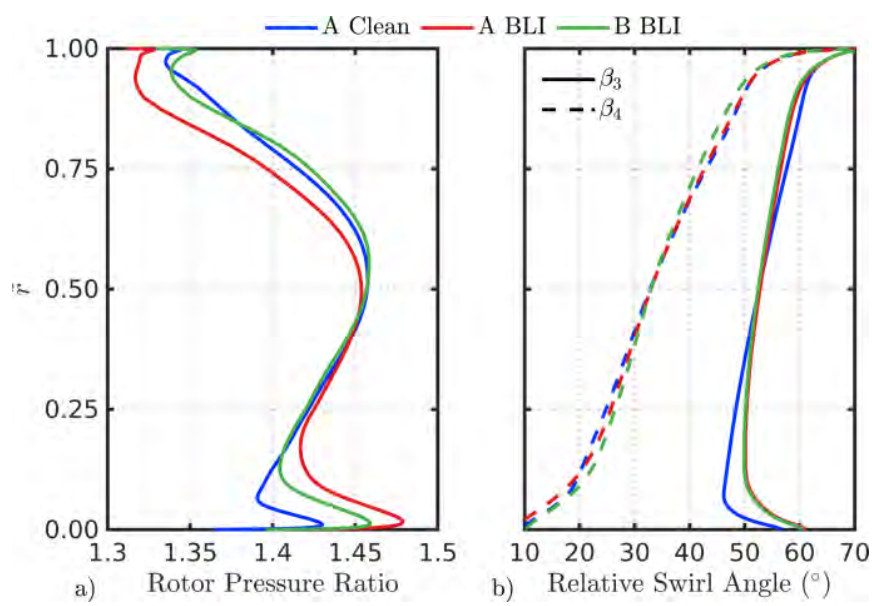

Figure 4 Spanwise distributions at the ADP of: a) rotor pressure ratio $b$ ) relative swirl angle

The leading edge metal angle of the OGV has been aligned with the rotor outlet flow to operate at minimum pressure loss incidence. The trailing edge metal angle has been set to release the flow axially at the ADP. A controlled radial profile of chord has been designed to reduce Lieblien's diffusion factor to a value under 0.35. Midchord-loaded sections have been stacked with $20^{\circ}$ of true sweep a compound true lean. True sweep has been used to reduce rotor-stator interaction noise (Woodward, et al., 2001). Compound lean has been implemented to reduce hub and casing corner separation. The proposed OGV design acts as an integrated structural/aerodynamic element and no additional structural strut is required (Goraj, et al., 2019) . Three blade sections of the rotor and OGV for Fan A are shown in Figure 5.

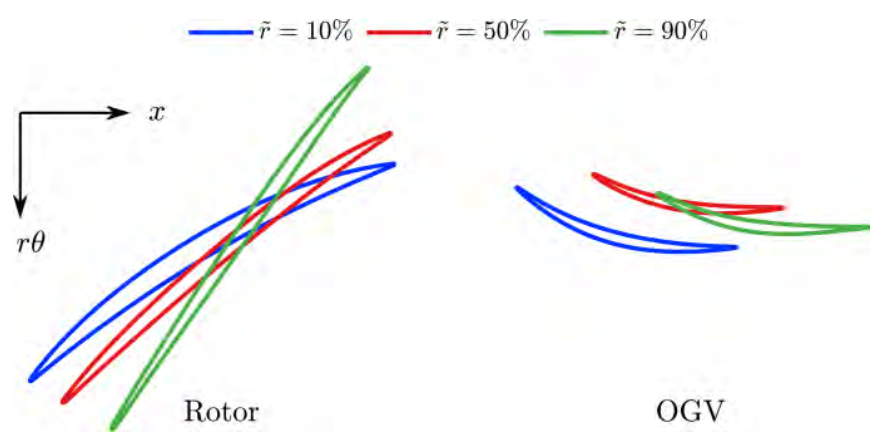

Figure 5 Rotor and OGV blade sections at 10,50 and $90 \%$ span of Fan A

\section{Effect of BLI on Fan A at ADP}

At cruise ADP, a severe and continuous hub-low radial total pressure distortion is ingested by the fan (Figure 3). This profile of stagnation pressure is correlated with the spanwise distribution of axial velocity. A deficit of axial velocity at the inner sections is balanced by an excess of velocity at the tip sections to keep the total mass flow the same as for clean flow.

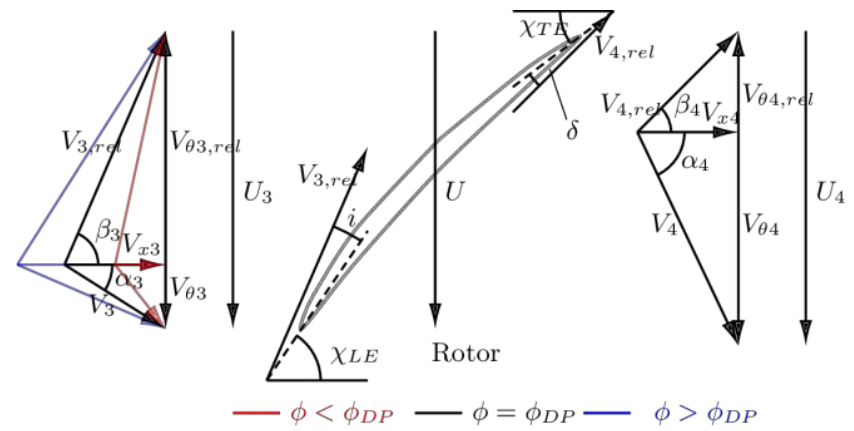

Figure 6 Rotor blade velocity triangles

Figure 6 presents a velocity triangle sketch illustrating the effect of flow coefficient changes caused by fuselage BLI. The axial velocity deficit found in the inner sections leads to the operation of these sections at high incidence. The tip sections, characterised by an excess of mass flow, operate at negative incidence. The midspan region remains operating at design point conditions. The changes in incidence are confirmed by the radial profiles of inlet relative swirl angle shown in Figure 4(b). Note that marginal changes in outlet relative swirl angle is caused by fuselage BLI for Fan A.

$$
\begin{gathered}
\Psi_{3}=\frac{\Delta h_{0}}{U_{3}^{2}}=\frac{U_{4} V_{\theta 4}-U_{3} V_{\theta 3}}{U_{3}^{2}} \\
=\frac{r_{4}^{2}}{r_{3}^{2}}-\frac{V_{x 3}}{U_{3}}\left(\tan \alpha_{3}-\frac{r_{4}}{r_{3}} \frac{V_{x 4}}{V_{x 3}} \tan \beta_{4}\right)
\end{gathered}
$$

The non-uniformity of the inlet axial velocity directly affects the radial work profile. Equation. 1 presents the nondimensional Euler work equation. For fuselage BLI distortion, 


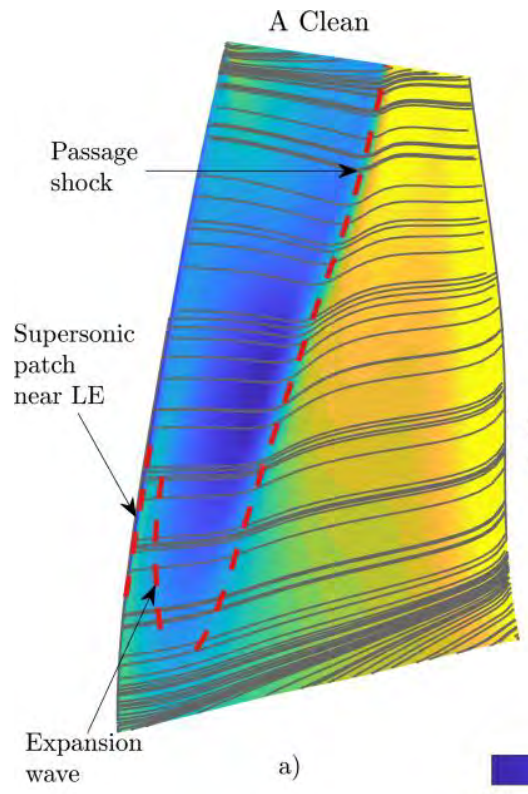

$-0.4$

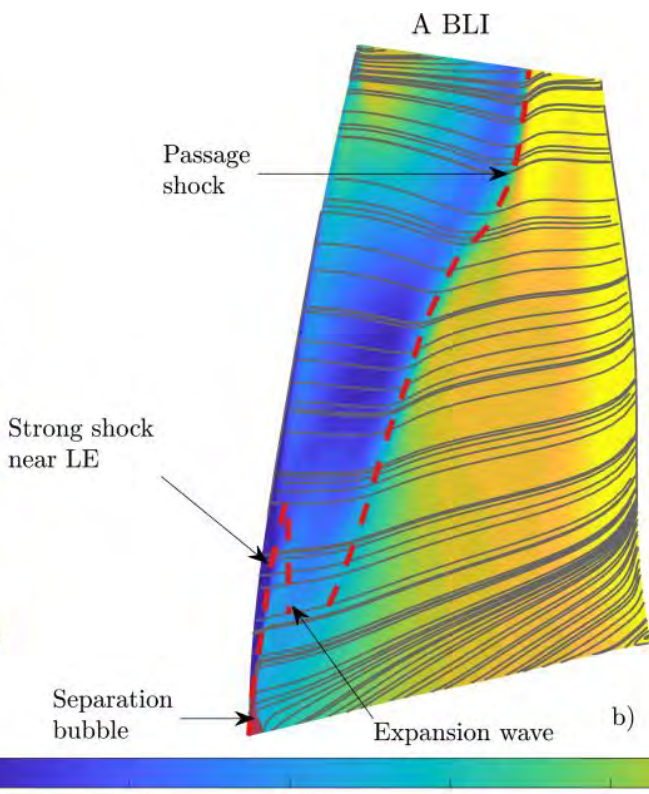

$-0.2$

$-0.1$

0

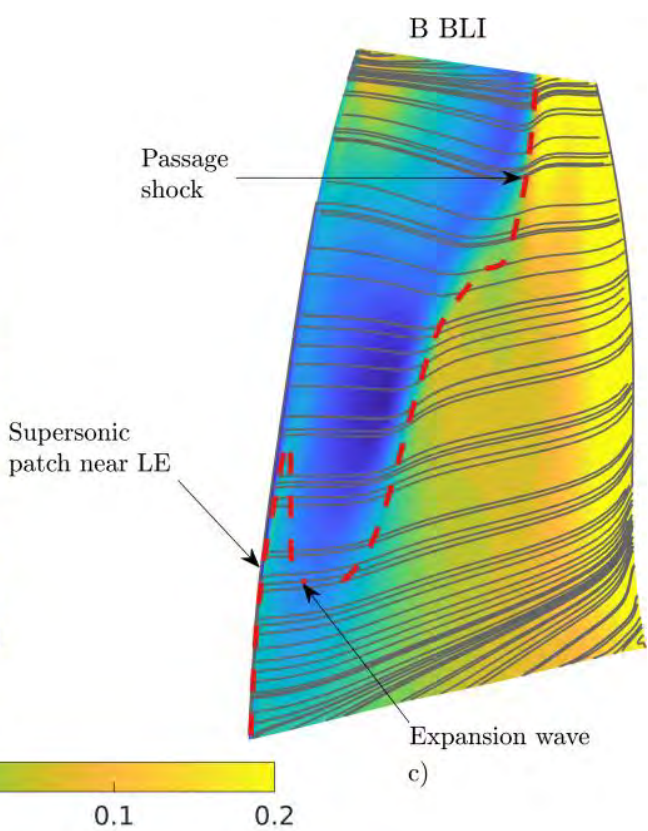

Figure 7 Contours of pressure coefficient on the rotor blade suction side along with surface streamlines at ADP: a) Fan A clean, b) Fan A BLI, c) Fan B BLI
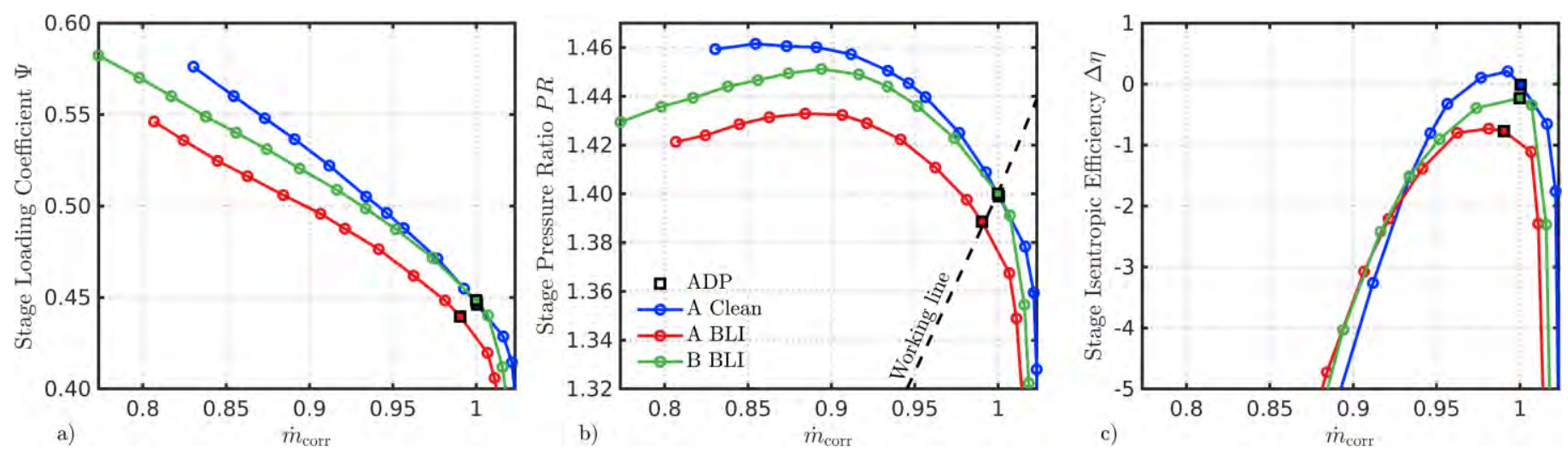

Figure 8 Effect of fuselage BLI on Fan A and B at 100\% corrected speed and cruise conditions: a) stage loading coefficient, b) stage pressure ratio, c) stage isentropic efficiency

the dominant term is the local flow coefficient $V_{x 3} / U_{3}$. Taking into account that $\beta_{4}<0$, the deficit of axial velocity of the inner sections corresponds to a local raise in work loading. The extra loading is linked to a rise in swirl at the rotor outlet $\alpha_{4}$, increasing the turning demand on the inner sections of the OGV. In contrast, the tip sections of the rotor (and OGV) get unloaded as result of the excess of axial velocity. These trends correlate with the changes in rotor pressure ratio observed in Figure 4(a) for Fan A.

To identify changes in the rotor shockwave structure due to fuselage BLI at the ADP, contours of pressure coefficient and surface streamlines on the suction side are presented in Figure 7. A shockwave extends down to about $10 \%$ span for Fan A ingesting uniform flow. A small supersonic patch is found near the LE between 20 and $40 \%$ span. The ingestion of fuselage BLI modifies the structure of the shockwave with a double mechanism: change of incidence and relative Mach number. Inner sections operate at higher incidence and a lower Mach number. As a result, the extent of the main shockwave is reduced by $10 \%$ of the span and a strong shock appears downstream of the LE. The interaction of the LE shock with the boundary layer causes the separation and later reattachement of the flow near the hub. In contrast, the tip sections operate at negative incidence and increased Mach number. Consequently, the shock moves further downstream choking the passage.

\begin{tabular}{|l|c|c|c|}
\hline & Fan A Clean & Fan A BLI & Fan B \\
\hline$\Delta \Psi(\%)$ & - & -1.49 & 0.50 \\
\hline$\Delta P R(\%)$ & - & -0.74 & 0.08 \\
\hline$\Delta \eta(\%)$ & - & -0.76 & -0.20 \\
\hline$\Delta F_{x}(\%)$ & - & -1.25 & -0.01 \\
\hline $\mathrm{SM}(\%)$ & 16.9 & 18.8 & 22.3 \\
\hline $\mathrm{CM}(\%)$ & 2.3 & 1.6 & 1.9 \\
\hline
\end{tabular}

Table 2 Aerodynamic performance of Fan A and B at cruise ADP

The overall effect of fuselage BLI distortion on the performance of Fan A at $100 \%$ corrected speed is presented in Figure 8 . Note that the comparison at ADP, quantified in Table 2 , is carried out at constant throttle setting, i.e., at a fixed 
nozzle non-dimensional flow. The larger extent of the unloaded blade region outbalances the extra work input of the inner sections, leading to an overall loss in stage loading coefficient. The off-design incidence with BLI deteriorates the stage isentropic efficiency. The combination of reduced loading and isentropic efficiency results in a drop in stage pressure ratio as shown in Figure 8. Although a true dragthrust split cannot be carried out for BLI installation, the loss in propulsor thrust consequence of fuselage BLI can be used to quantify the drop in efficiency of the system. Assuming a 1D isentropic expansion of the flow through the nozzle and constant average inlet properties, the thrust generated can be expressed as $F_{x}=\dot{m}\left(V_{j e t}-V_{0}\right)$. An overall drop in thrust of $1.25 \%$ is observed in Table 2 due to BLI.

The drop in stage loading and stage pressure ratio at ADP is consistently found along the $100 \%$ corrected speedline. The tip sections, which at ADP operate at negative incidence, reach design conditions for lower mass flow rates. As a results, higher isentropic efficiency is linked to BLI at reduced corrected mass flow. Additionally, it increases the stability margin (SM) by $1.9 \%$ as shown in Table 2 In contrast, the higher Mach numbers found at the tip section with BLI lead to a reduction of the choking margin $(\mathrm{CM})$ by $0.7 \%$.

\section{Fan B}

A series of design steps have been applied to develop Fan A into Fan B, a fan design optimised for fuselage BLI. These are based on the philosophy design proposed by Castillo Pardo $\&$ Hall (2019) for low speed fuselage fans.

The first step is the realignment of the rotor LE. BLI distortion increases the incidence at the inner sections whilst causes negative incidence at the tip. Fan B aligns the LE for minimum pressure loss operation up to $75 \%$ span. The optimum alignment of the blade LE reduces the acceleration of the flow around it. As a result, the strong shock observed in for Fan A near the LE is not present for Fan B (Figure 7).

Although the flow is assumed axisymmetric during the design phase, the fan must be tolerant to incidence excursions caused by $3 \mathrm{D}$ distortion. To increase the tolerance of the tip section and extend its stable operating range, the tip section has been restaggered to operate with $2.5^{\circ}$ of negative incidence at ADP. A larger value of negative incidence would lead to increased choking losses and reduced choking margin. Therefore, the chosen value is a compromise between improved operability and passage choking effects.

The second step is the modification of the radial work distribution. Fuselage BLI increases the loading on the inner sections as shown in Figure 4(a). This is followed by a rise in the turning required to the lower part of the OGV. To improve the efficacy of the whole stage, the inner sections of Fan B have been unloaded by reducing its turning (Figure 4). As a collateral effect, the turning demand on the OGV hub is alleviated. To meet the performance requirements and compensate the reduced loading of the inner section, the region between 60 and $80 \%$ span has been further loaded (Figure 4(a)). The extra load has been attained by increased blade turning as shown in Figure 4(b). The combination of higher blade turning and high inlet relative Mach number in this region results in the movement of the passage shock further downstream, choking the passage (Figure 7(c)). The chord distribution originally designed for Fan A has been chosen for Fan B. It ensures the Lieblien's diffusion factor remains under 0.35 . To generate comparable results, the technology used for the OGV of Fan A has been chosen as well for Fan B. The LE has been adjusted across the span to operate at minimum loss incidence.

The overall aerodynamic performance of Fan B at ADP is presented in Table 2. Fan B stage is able to meet the performance requirements at ADP with a minor decrease in isentropic efficiency compared with Fan A in clean inflow. Note that Fan B is able to generate the required thrust at a higher efficiency compared to Fan A. The design philosophy of Fan B successfully recovers $0.3 \%$ of choking margin and it extends its stability margin by $3.5 \%$ relative to Fan A.

From the above it can be concluded that Fan B performs as well with BLI distortion as Fan A in clean conditions at the ADP. This is confirmed in Figure 8 by the overlapping performance of both Fans at ADP. Below $\dot{m}_{\text {corr }}=0.97$ the performance of both fans differs. The work input drops and subsequently the pressure ratio. To explain this trend, an order of magnitude analysis of Equation 1 is carried out. It is applied for Fan A and Fan B with clean and BLI inflows respectively. The local flow coefficient $V_{x 3} / U_{3}$ is the driving term on the work loading. The evolution of this term with corrected mass relative to its ADP value flow is shown in Figure 7 for two blade sections: 25 and $75 \%$ span. $\varepsilon$ represents the average rate of growth of the local flow coefficient with mass flow. For the outer section, $\varepsilon$ is greater for clean inflow. When the mass flow is reduced, the work load on this section grows at a lower rate for BLI than for clean inflows. The opposite is found for the inner section, where the growth rate is higher for BLI. The larger extent of the unloaded region dictates the overall effect of BLI on the work loading coefficient. Consequently, blade loading increases at a higher rate for clean condition than for fuselage BLI, as shown in Figure 8(a). Higher efficiency is observed in Figure 8(b) for BLI conditions. This is caused by reduced load and lower incidences found on the tip for BLI. The drop in loading outbalances the enhanced efficiency, leading to a reduction in pressure ratio away from ADP.

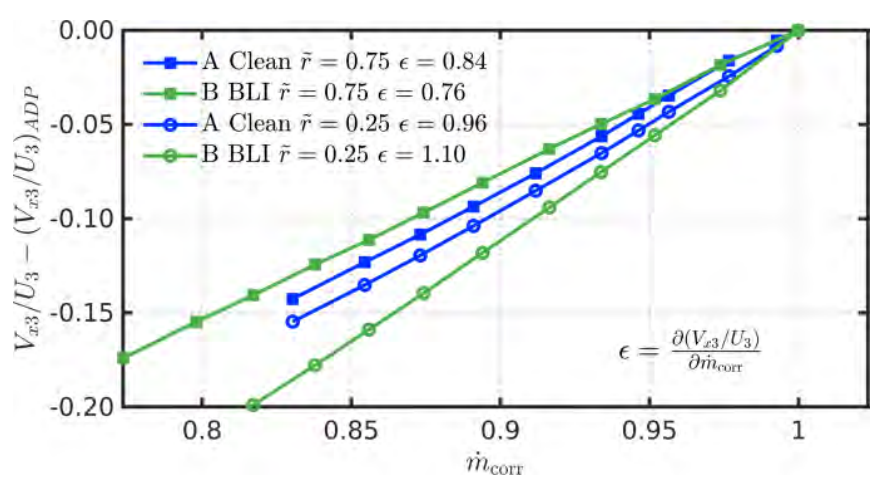

Figure 7 Evolution of local flow coefficient with corrected mass flow at cruise $100 \%$ speed

\section{CRUISE OFF-DESIGN PERFORMANCE}

Figure 10 presents the CFD based cruise fan map for Fan $\mathrm{A}$ and Fan B with clean and fuselage BLI inflows respectively. Isolines of 50 to $110 \%$ corrected speed are shown for stage 
pressure ratio and stage isentropic efficiency. Note that the isentropic efficiency is referenced to its value at clean ADP condition. At a constant corrected speed, both fans exhibit the same level of performance for both inflows near ADP. However, away from ADP the performance with BLI is reduced. This is due to the growth of local flow coefficient previously explain, which results in higher work input for clean inflow. Additionally, the growth of rate of the local flow coefficient across the span is more uniform for clean than for BLI (Figure 9). As a result, less uniform and more severe offdesign inflow conditions are found for BLI as the mass flow reduces at cruise. Subsequently, a drop in efficiency is observed in Figure 10 for low mass flow rates. Regardless of the lower efficiency, Fan B consistently increases the stability margin at all speed. The rise in stability margin ranges from $4 \%$ at high speed to $10 \%$ at low speed.

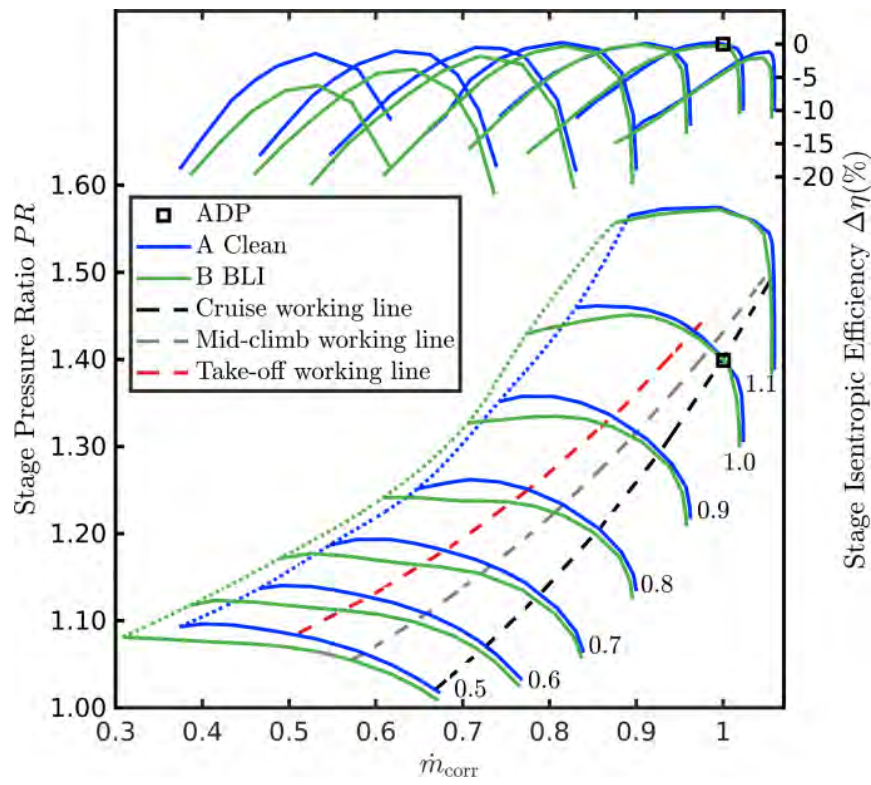

Figure 8 Cruise fan map of Fan A and Fan B

\section{TAKE-OFF OFF-DESIGN PERFORMANCE}

Fan B has been designed to perform optimally at cruise ADP, where it offers its biggest potential to the BLI aircraft concept. Although of lower relevance, its performance at other flight phases cannot be compromised. The increased stability margin attained through controlled tip resstaggering should alleviate the requirements place on this sections at operating conditions where higher loading is applied on the upper section of the blade.

Figure 3compare the inflow conditions at ADP with two off-design phases: take-off and mid-climb. The level of distortion found at take-off is greatly reduced compare to cruise, whilst mid-climb is an intermediate situation. The discrepancy in inflows is caused by the specific fuselage boundary layer characteristics at each flight phase.

Fan B was designed for a severe and continuous hub-low distortion. Consequently, take-off condition effectively becomes a pseudo tip-low distortion. This operating condition becomes a challenging condition to ensure stable operation. In addition to the "distorted" inlet conditions, Figure 10 shows that the take-off working line moves substantially towards the stability line. Mid-climb is not further studied as it is an intermediate condition between take-off and cruise.

CENTRELINE's fuselage fan is driven by an electric motor. The motor was sized by Wortmann (2018) for optimum performance across the mission. During take-off, the maximum available torque limits the attainable fan performance. This is illustrated in Figure 11, where the torque required by the fan is plotted along the operating line for cruise and take-off. Note that torque is normalised by the maximum torque delivered by the motor. The limiting operating point for take-off corresponds to a normalised torque with a unity value, a stage pressure ratio of 1.2 and a corrected speed of $72 \%$. This operating point is chosen for take-off.

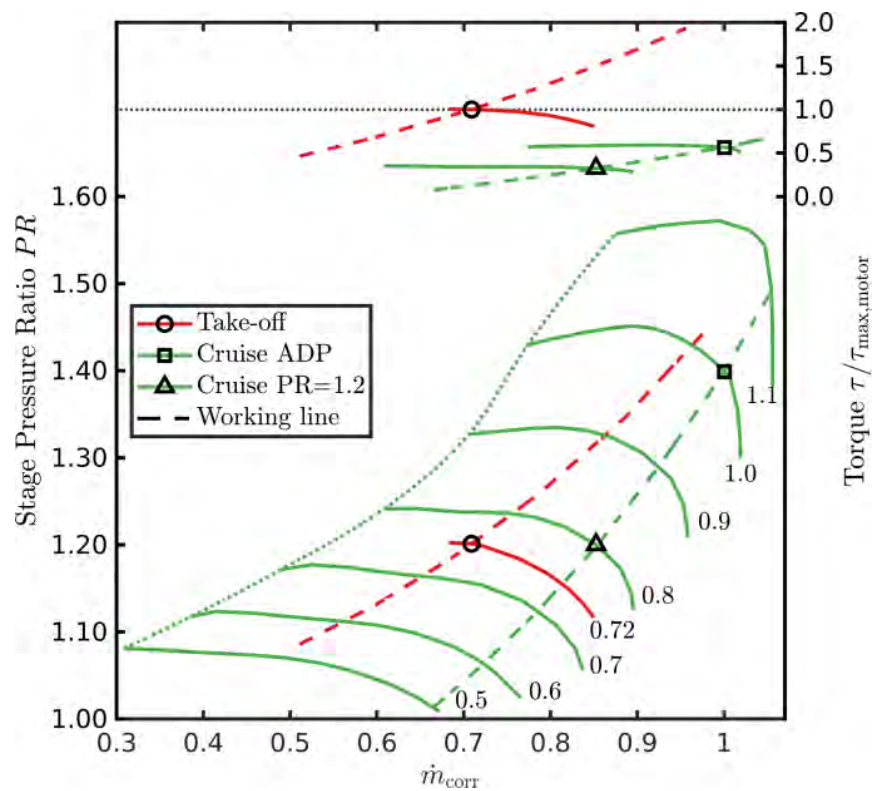

Figure 9 Cruise and take-off fan maps of Fan B

Three mechanisms are found to modify the aerodynamics at take-off relative to an auxiliary point at cruise with the same pressure ratio: increased Reynolds number, reduced ram pressure and pseudo tip-low.

Reynolds number at take-off is approximately 2.7 times higher. In the absence of distortion this would result in thinner boundary layers, increased capacity and efficiency.

At take-off the flight Mach number is 0.25 , this reduces the ram pressure and moves the working line to lower flow coefficients. The off-design flow coefficient deteriorates the efficiency and increases incidence across the span. Figure 12(b) compares the relative swirl angle at take-off and cruise $\mathrm{PR}=1.2$. The angles for ADP are included for reference. At take-off, the increase in incidence across the span is observed relative to $\mathrm{ADP}$. The incidence at cruise $\mathrm{PR}=1.2$ is fairly similar to ADP except at the hub, where increased angles are observed. This is caused by the non-uniform spanwise growth in flow coefficient with mass flow and leads to a further increased in load near the hub (Figure 12(a)).

A weak and continuous hub-low distortion is ingested at take-off (Figure 3). The fan response to this inflow is similar to the cruise case but of smaller magnitude. It unloads the tip and rises the work input near the hub. This is presented in 
Figure 12(a) in terms of rotor pressure ratio. For a fan designed for clean flow, hub-low distortion increases the incidence near the hub and becomes negative at the tip. However, Fan B has been designed for a severe hub-low distortion. Consequently, the weaker distortion increases the incidence at the tip sections whilst reduces its value in the inner sections. This is confirmed in Figure 12(b) by an increase in incidence with radius.
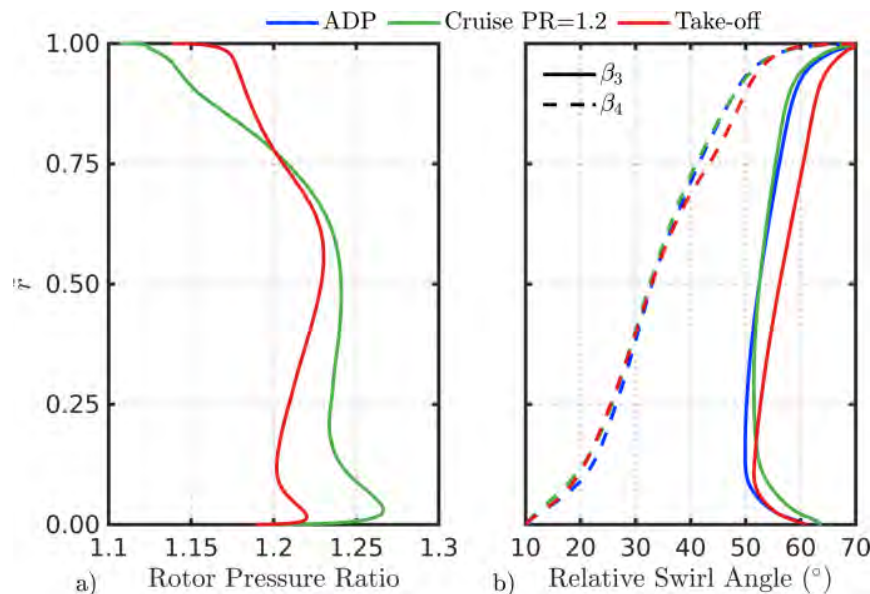

Figure 10 Spanwise distributions at take-off of: a) rotor pressure ratio b) relative swirl angle

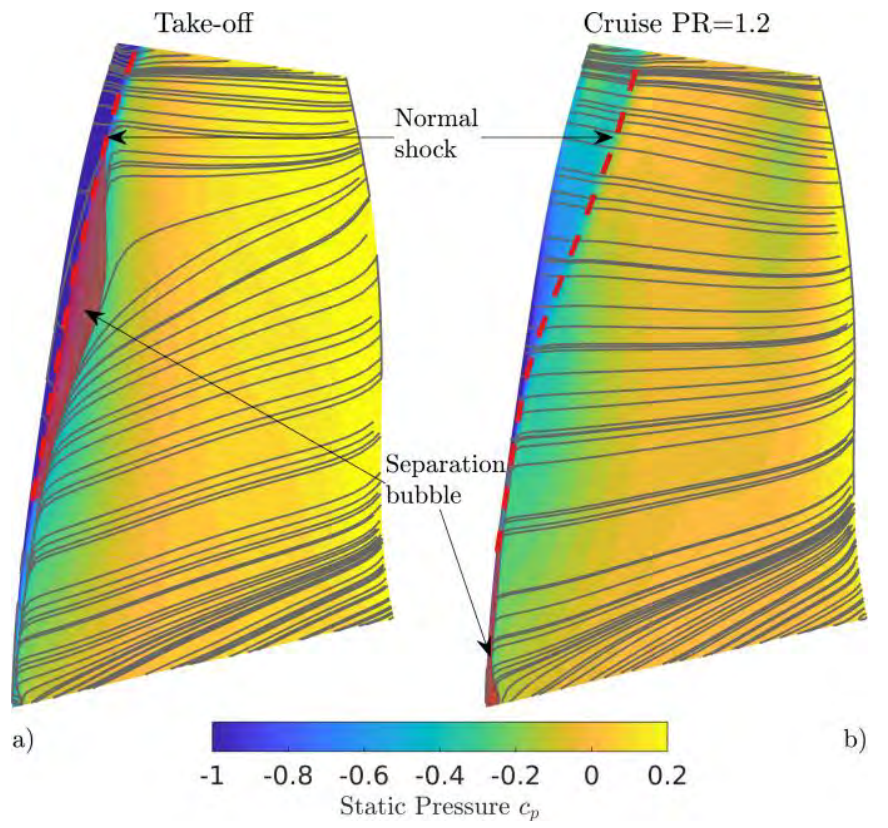

Figure 11 Contours of pressure coefficient on Fan $B$ rotor blade suction side along with surface streamlines: a) take-off b) cruise $P R=1.2$

At take-off, the operation at reduced flow coefficient and increased incidence converts the passage shock into a strong normal shock located near the leading edge (Figure 13 (a)). The normal shock interacts with the boundary layer, generating a separation bubble between 40 and $80 \%$ span. Although the flow reattaches, the deviation at the trailing edge increases as shown in Figure 12(b). The restaggering used at the tip reduces the incidence and avoids flow separation. For cruise $\mathrm{PR}=1.2$, the inflow conditions in the upper part of the blade are close to ADP. Consequently, the strength of the shock is weaker. Separation is only observed in the inner sections and is associated to high incidence.

The shock-boundary layer interaction found for take-off reduces the operating range relative to cruise, as shown in Figure 9 for the $72 \%$ speed line. The last stable point calculated using steady RANS is used to evaluate the operating range and stability margin. Although this is not an accurate measurement, it provides an insight on the approximate operability of the fan. The overall performance at take-off is a balance between the positive Reynolds number effect and the more severe operating conditions. Note that the use of a single map generated for ADP would result in the wrong performance at off-design. This emphasises the necessity of considering off-design operation during the design phase.

\section{CONCLUSIONS}

1. A baseline midspan loaded fan has been designed and tested for clean and cruise BLI inflows.

2. The effect of the ingestion of BLI distortion on the datum fan at cruise ADP has been analysed:

a. The inner blade sections operate high incidence and increased work input whilst the tip gets unloaded with negative incidence.

b. The overall effect of BLI at ADP is the reduction in work loading and efficiency.

3. A fan design optimised for cruise fuselage BLI has been developed by:

a. Realigning the leading edge with the inflow.

b. Restoring the undistorted work and diffusion factor distributions.

c. Restaggering the tip with negative incidence for improve operability.

4. The new design increases the thrust delivered at ADP by $1.24 \%$ with improved stability and choking margins.

5. The new fan is able to increase the stability margin by 4 to $10 \%$ relative to the datum design.

6. The relevance of off-design consideration has been presented for cruise and take-off. The latter constitutes the most challenging operation for fuselage fans.

7. The improved operability of Fan B alleviates the adverse inlet conditions found at the tip during take-off, ensuring stable operation.

\section{ACKNOWLEDGMENTS}

This research is part of the CENTRELINE project, which has received funding from the European Union's Horizon 2020 research and innovation programme under Grant Agreement No. 723242. The authors are grateful to Turbostream for the use of their solver. Phoenix Tse at the Whittle Laboratory and Daniel Giesecke from the Tecnische Universität Braunschweig are thanked for their technical advice, comments and suggestions. 


\section{NOMENCLATURE}

$\begin{array}{cl}\text { Roman symbols } \\ F_{x} & \text { Thrust } \\ h & \text { Enthalpy } \\ p & \text { Pressure } \\ r & \text { Radius, radial coordinate } \\ T & \text { Temperature } \\ U & \text { Rotor blade speed } \\ V & \text { Velocity }\end{array}$

\section{Greek symbols}

$\begin{array}{ll}\alpha & \text { Absolute swirl angle } \\ \beta & \text { Relative swirl angle } \\ \theta & \text { Circumferential coordinate } \\ \rho & \text { Density } \\ \tau & \text { Torque } \\ \chi & \text { Blade metal angle }\end{array}$

\section{Non-dimensional groups}

$\begin{array}{cl}c_{p} & \text { Pressure coefficient } \\ \mathrm{CM} & \text { Choking margin }=\frac{\dot{m}_{\text {corr }, \text { choke }}}{\dot{m}_{\text {corr }, A D P}}-1 \\ \dot{m}_{c o r r} & \text { Corrected mass flow }=\frac{m / \dot{m}_{A D P} \sqrt{T_{0} / T_{0, A D P}}}{p_{0} / p_{0, A D P}} \\ \mathrm{PR} & \text { Stage pressure ratio } \\ \tilde{r} & \text { Span fraction } \\ \mathrm{SM} & \text { Stability margin }=1-\frac{\dot{m}_{\text {corr }, \text { stable }}}{\dot{m}_{\text {corr }, A D P}} \\ \eta & \text { Stage isentropic efficiency } \\ \Psi & \text { Stage loading coefficient }\end{array}$

\section{Subscripts}

$0 \quad$ Stagnation quality

1 Value at highlight plane

3 Value at rotor inlet

$4 \quad$ Value at rotor outlet

$5 \quad$ Value at OGV outlet

$x \quad$ Axial component

$\theta \quad$ Circumferential component

\section{Acronyms}

$\begin{array}{cl}\text { ADP } & \text { Aerodynamic Design Point } \\ \text { BLI } & \text { Boundary Layer Ingestion } \\ \text { CFD } & \text { Computational Fluid Dynamics } \\ \text { LE } & \text { Leading Edge } \\ \text { OGV } & \text { Outlet Guide Vane } \\ \text { TE } & \text { Trailing Edge } \\ \text { VTP } & \text { Vertical Tail Plane }\end{array}$

\section{REFERENCES}

Brandvik, T. \& Pullan, G., 2011. An Accelerated 3D NavierStokes Solver for Flows in Turbomachines. Journal of Turbomachinery, Volume 133, p. 021025.

Castillo Pardo, A. \& Hall, C. A., 2019. Aerodynamics of Boundary Layer Ingesting Fuselage Fans. Canberra, International Society of Air Breathing Engines.
Goraj, Z., Kowalski, M. \& Goliszek, B., 2019. Optimisation of the loading structure for Propulsive Fuselage Concept. Canberra, International Society of Air Breathing Engines.

Gunn, E. J. \& Hall, C. A., 2014. Aerodynamics of Boundary Layer Ingesting Fans. Dusseldorf, American Society of Mechanical Engineers.

Gunn, E. J. \& Hall, C. A., 2017. Non-Axisymmetric Stator Design for Boundary Layer Ingesting Fans. Charlotte, American Society of Mechanical Engineers.

Hall, C. A., Schwartz, E. \& Hileman, J. I., 2009. Assessment of Technologies for the Silent Aircraft Initiative. Journal of Propulsion and Power, Volume 25, p. 1153-1162.

Jerez Fidalgo, V., Hall, C. A. \& Colin, Y., 2012. A Study of Fan-Distortion Interaction Within the NASA Rotor 67 Transonic Stage. Journal of Turbomachinery, Volume 134, p. 051011.

Mårtensson, H. E. L. L. A., 2019. Design Conditions for an Aft-Mounted Fan with Boundary Layer Ingestion. Canberra, International Society of Air Breathing Engines.

NUMECA International, 2016, 2016. Autogrid5. s.1.:s.n.

Sandercock, D. M. \& Sanger, N. L., 1974. Some Observations of the Effects of Radial Distortions on Performance of a Transonic Rotating Blade Row, Cleveland: National Aeronautics and Space Administration.

Sanger, N. L., 1979. Effect of Rotor Meridional Velocity Ratio on Response to Inlet Radial and Circumferential Distortion, Cleveland: National Aeronautics and Space Administration.

Schmidt, J. F. \& Ruggeri, R. S., 1978. Performance with and without Inlet Radial Distortion of a Transonic Fan Stage Designed for Reduced Loading in the Tip Region, Cleveland: National Aeronautics and Space Administration.

Seitz, A. et al., 2018. Concept Validation Study for Fuselage Wake Filling Propulsion Integration. Belo Horizonte, International Council of Aeronautical Sciences.

Spalart, P. \& Allmaras, S., 1992. A One-equation Turbulence Model for Aerodynamic Flows. Reno, American Institute of Aeronautics and Astronautics, p. 439.

Uranga, A. et al., 2014. Preliminary Experimental Assessment of the Boundary Layer Ingestion Benefit for the D8 Aircraft. National Harbor, American Institue of Aeronautics and Astronautics, p. 0906.

van Sluis, M., 2020. D3.03 - Final PFC Aircraft Aerodynamic Design and Performance, s.l.: s.n.

Woodward, R., Elliott, D., Hughes, C. \& Berton, J., 2001. Benefits of Swept and Leaned Stators for Fan Noise Reduction. Journal of Aircraft, 38(6), pp. 1130-1138. Wortmann, G., 2018. D4.04 - Electric Machinery Preliminary Design Report, s.1.: s.n. 